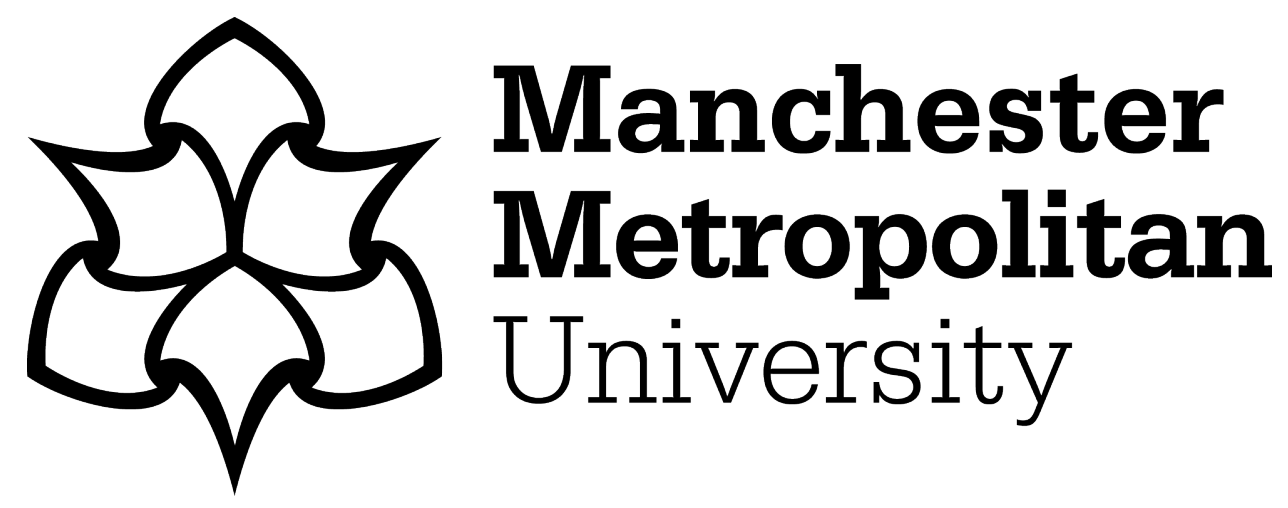

Lo, SHR (2016) The CIVA system for engineering education. International Journal of Mechanical Engineering Education, 44 (4). pp. 302-312. ISSN 0306-4190

Downloaded from: https://e-space.mmu.ac.uk/617211/

Version: Accepted Version

Publisher: Sage Publications Ltd.

DOI: https://doi.org/10.1177/0306419016669031

Please cite the published version 


\title{
The CIVA system for engineering education
}

\author{
S H R Lo'
}

\begin{abstract}
Engineering education in higher education is facing multiple and significant challenges due to the changing requirements for future professional engineers and the changing landscape of higher education. How to raise the standard and quality of engineering courses to meet the demands of the fast evolving industry and society, how to improve the employability of graduates by developing the mentality and competence of professional engineers, and how to improve the inclusiveness to maximise the benefits of widening participation and internationalisation of $\mathrm{HE}$ are some key issues that need to be addressed. This paper presents an innovative system for engineering education, the CIVA (standing for Coursework-driven teaching \& learning process, Integrated teaching approach, Verification \& Validation guided quality learning and professional development, and Active support mechanism) system. The CIVA system aims to address the above mentioned key issues in engineering education and represents a new way to manage the teaching and learning process in order to achieve a high quality engineering education outcome that is characterised by high academic standard and quality, high inclusiveness and high employability. An example of implementation of the CIVA system for a structural vibration unit is provided for illustration.
\end{abstract}

Furthermore, the CIVA system provides a framework in engineering education that is responsive and customisable to the requirements of both the learners and the employers. With further development, the CIVA system is promising to make a significant contribution to modernising engineering education.

\section{Keywords}

Reform of engineering education, employability, inclusiveness.

\footnotetext{
${ }^{1}$ School of Engineering, Manchester Metropolitan University, Chester Street, Manchester M1 $5 G D$, UK
}

Corresponding author:

Sophie Hong Rui Lo, School of Engineering, Manchester Metropolitan University, Chester Street, Manchester M1 5GD, UK

Email: s.h.r.lo@mmu.ac.uk 


\section{Introduction}

Engineering education in higher education (HE) is of critical importance to modern industry and society, especially with the ever increasing trend that technology plays a significant role in all aspects of people's lives. One of the main purposes of engineering education in $\mathrm{HE}$ is to produce graduates who have the mentality and the competence to pursue professional engineering careers. However, engineering education faces multiple challenges. Among them, graduate employability is a key issue especially in the era when industries undergo rapid and significant changes all the time. In addition, internationalization of higher education and widening participation for improving social mobility all require a new strategy to achieve effective inclusiveness of the education provision [1][2][3]. Some of these challenges have become particularly acute for analytical subjects as they require some pre-requisite knowledge and skills in general. On the other hand, a common characteristic of our contemporary students is that when they decide how they spend their time at the university, they do not give sufficient emphasis on academic study [4]. In addition, due to the much increased tuition fees, the financial pressure for attending university makes the part-time job a high priority for many students, especially for those from disadvantaged social economic backgrounds. To take an evidence-based approach, starting from these facts, an innovative system, the CIVA (standing for Coursework-driven teaching \& learning process, Integrated teaching approach, V\&V guided quality learning and professional development, and Active support mechanism) system has been designed to find a solution. The CIVA system aims to address the above mentioned key issues in engineering education and represents a new way to manage the teaching and learning process in order to achieve a high quality engineering education outcome that is characterized by high academic standard and quality, high inclusiveness and high employability.

It has been acknowledged widely that for the engineering education reform to be successful, an active involvement of industry and a close collaboration between industry and engineering departments are of crucial importance. The implementation of the CIVA system has further demonstrated these requirements and has also highlighted some possibilities of how these may be achieved with benefits for all stakeholders [5][6].

The CIVA system provides a framework in engineering education that is responsive and customisable to the requirements of both the learners and the employers. With further development, the CIVA system has the potential to make a significant contribution to modernising engineering education.

In the following sections, it will outline

- An overview of the CIVA system 
- An example of implementation of the CIVA system

- Evaluation of the CIVA system

- Underpinning rationale of the CIVA system

- Potential benefits of the CIVA system in reforming engineering education

\section{An overview of the CIVA system}

The CIVA system consists of four main aspects:

- Coursework-driven teaching \& learning (CDTL) process,

- Integrated teaching approach (ITA),

- Verification \& Validation (V\&V) guided quality learning and professional development, and

- Active support mechanism (ASM).

Within the CDTL process, the students are set the summative coursework at an early stage of the academic year and it is recommended strongly that each student use a unique set of data to make the coursework individual. The coursework is designed carefully to incorporate the knowledge and skills that are consistent with the required learning outcomes of the syllabus. This approach is designed to help the students become self-driven for their learning so that they actively engage with the relevant teaching provision that include lectures, tutorials, computing sessions and laboratories as scheduled taught elements, as well as other learning resources, e.g., those from the internet and social media.

ITA here is in the context of teaching engineering analysis subjects and it means that while the following 5-key skills are taught as individual topics, they are applied in an integrated manner to the same example problems.

(a) System idealisation (Making assumptions to obtain an analysable system)

(b) Mathematical modelling (Applying the physical laws to set up the governing equations)

(c) Theoretical analysis (Obtaining mathematical solutions by solving equations)

(d) Computer simulation (Using computer software to obtain numerical solutions)

(e) Physical testing (Testing and data processing to determine system parameters and to measure excitation/response for determining system behaviour)

Learning and practicing the integrated approach of problem-solving is highly beneficial for students. It enhances student employability as the knowledge, skills and experience gained are directly relevant to professional engineering practice. 
In industry, $\boldsymbol{V} \boldsymbol{\&} \boldsymbol{V}$ is the process of confirming that the digital model is an adequate representation of the physical counterpart and it should take place at every stage of the virtual product development process. In engineering education, the V\&V process becomes a powerful tool for quality learning as it requires students to apply the different knowledge and skills learned in the subject to the same problem and drives students to initiate further investigations to understand and improve the correlation between the different sets of result.

The ASM represents a dynamic and smart student learning support system with the main aim of achieving inclusiveness. 'Dynamic' means actively searching for study barriers associated with different groups of students (e.g., students with or without prior maths study, whether or not being direct entrants) or different scenarios (e.g., with or without attending lectures for whatever reasons) while 'smart' means examining students' performance to identify areas of concern (e.g., from formative assessment results). Once the barriers and weak areas have been identified, corresponding solutions and support will be created. For example, for my subjects, pre-requisite knowledge, including maths topics and basic Matlab skills, were provided before teaching started for preparation, special 'catch-up' sessions were added for direct entrants, weekly summaries of T\&L contents and requirements were uploaded in Moodle, as examples of being 'dynamic'. On the other hand, based on students' performance in formative assessments, various targeted 'follow-up' sessions were added, as an example of being 'smart'. However, how effective and helpful these solutions can be depends on whether the motivation for study is there in the first place and, therefore, the ASM works well with the CDTL approach.

\section{An example of implementation of the CIVA system}

A final year dynamics coursework of structural vibration is a representative example of the CIVA system implementation. Some highlights of the different aspects are given below.

Figure 1 illustrates the CDTL process. The students were given a preview of the coursework at the start of the year. Lectures, tutorials, formative activities (FA) and feedback provide the key knowledge and skills required for doing the coursework. For example, in FA1, a single degree of freedom (SDOF) system was used for students to practise the 5-key skills learned in the lectures and, in FA2, vibration testing and subsequent signal processing for a 3-beam structure were carried out to gain understanding of structural modal analysis and practise modal testing. These help prepare students for the summative coursework. 


\section{Coursework related teaching \& learning activities}

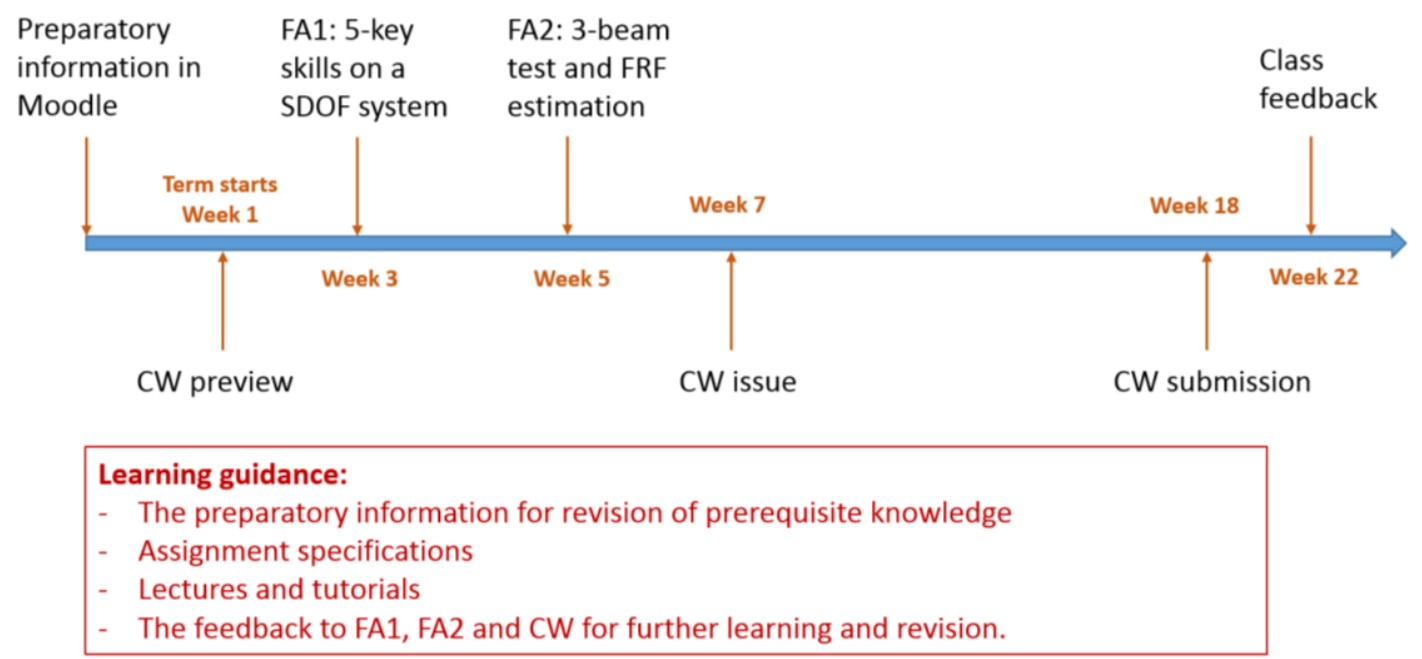

Figure 1 Dynamics coursework related T\&L activities and the timeline

The coursework was set as an investigation of a 3-rotor torsional vibration system. Figure 2 shows the 3-rotor test rig and a schematic diagram of the test setup. Each student was assigned a unique combination of the shaft (material type and diameter) and additional masses on the rotors (attached magnets). The industry standard software LabVIEW was used to generate a signal to excite the system and to acquire the measured excitation and response signals into computer for further processing and analysis using Matlab.

3-rotor torsional vibration testing

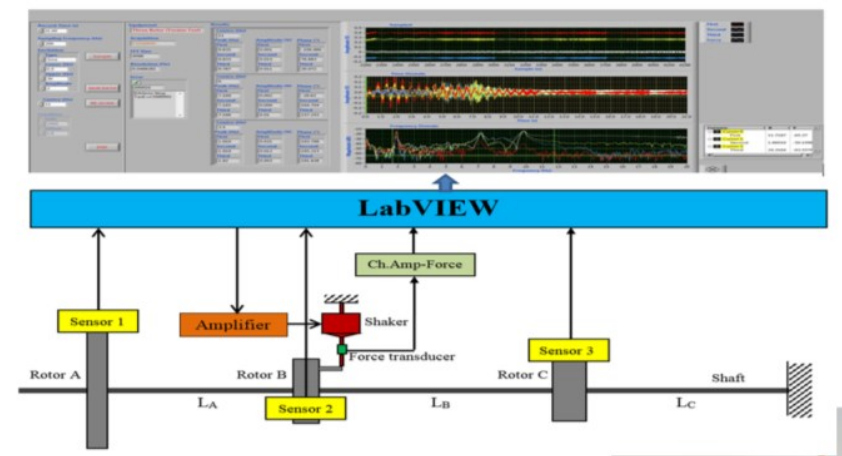

\section{Schematic diagram}

3-rotor test rig \& additional magnets
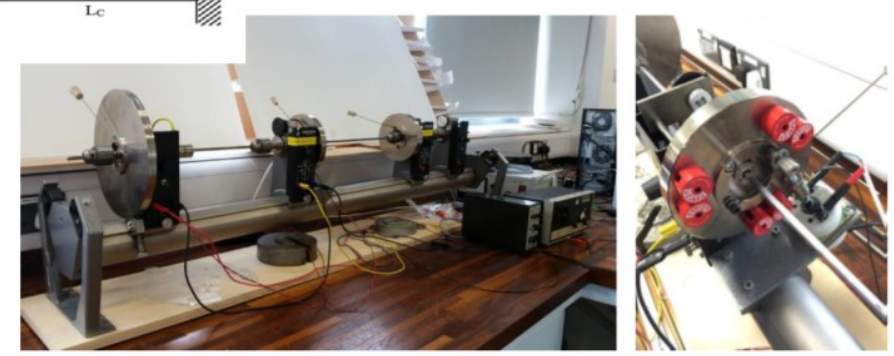

Figure 2 The 3-rotor vibration system and the schematic diagram of testing 
The coursework brief provided a guidance to students by indicating the subtasks involved. From Figure 3 it can be seen that in doing the coursework, the set of knowledge and skills covered by the ITA is applied and $V \& V$ is carried out among the theoretical solution, computer simulation result and experimental result.

Dynamics assignment:

\section{Investigation of a 3-rotor vibration system}

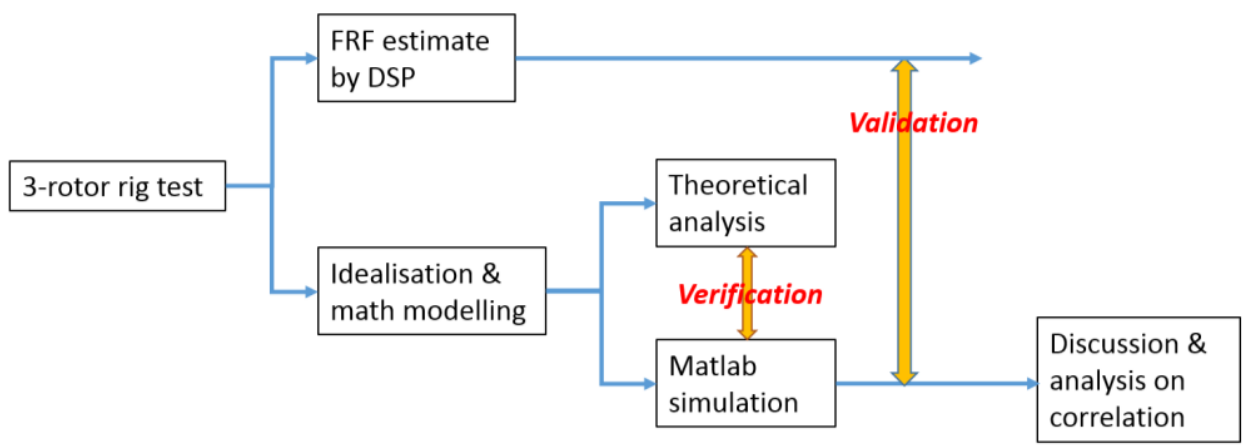

Figure 3 Dynamics coursework scheme

\section{Evaluation of the CIVA system}

To evaluate the CIVA system, feedback was gathered from various sources including Internal Student Survey (ISS), in-class questionnaires, and one-to-one and group conversations with students. Below is a summary of the key points made in the student feedback.

\section{Positive comments:}

(1) Students appreciate the value of the integrated teaching and the multi-skills training in enhancing their employability.

(2) Students like the setup that the coursework is linked to the technical topics that are taught in the unit so that doing the coursework helps them learn and understand better the taught theories through the application. Since the theories are applied in the verification process of the computer models, this helps them build up confidence before the end of year exam.

(3) Students like the fact that by doing the $V \& V$, they know themselves whether the results that they have obtained are correct or not. They enjoy the sense of achievement when the correlation is good or has been improved. However, they could also get frustrated during the 'debugging' process if it took long or the errors could not be identified. 
(4) Students like the 'hands-on' experience in the laboratories, even though it was limited due to the timetable constraint.

\section{Issues raised:}

The main issue that has been raised by students regarding the CIVA type of coursework is about spending too much time to complete the coursework. A more detailed analysis has identified the main causes for this issue.

(a) The CIVA type of coursework requires the application of a range of knowledge and skills including theoretical analysis, computer simulation, experimental testing and test data processing, etc..

(b) The $\mathrm{V} \& \mathrm{~V}$ process often takes up a large proportion of the coursework time and the amount of time can be unpredictable for an individual student as a good correlation between different results depends on all results being viable.

(c) In order for students to be able to apply the theories for the verification purpose, they have to understand and revise the taught materials. So, in effect, doing the coursework has required them to revise the theories earlier in the cycle rather than nearer the examination period. However, this revision time spent was counted by some students as part of the time for doing coursework.

Based on this analysis, it can be seen that (a) and (b) are directly related to the high standard and quality of work contained in the coursework. Essentially this CIVA type of coursework requires the students to carry out the investigation using a similar method and process to what the professional engineers do in their jobs and therefore a similar experience is received.

However, since this unit was taught within a course together with a set of other units, the time balance factor needs to be taken into account. So the following adjustments are made.

\section{Improvement measures:}

Improvement measures to address the above points include

(a) Adjusting the course design such that an improved scheme of progressive and staged learning is made. For example, in this case, some of the Matlab skill development is moved to the previous year. This reduced learning time for the software addresses partially the timing problem.

(b) Modifying the coursework specifications such that the V\&V process is carried out and confined within each sub-task, i.e., there is no carry-forward error between different sub-tasks, although it is made clear that this would not be the practice in real-world industrial investigations. 
(c) Motivating the students to keep up to date with the learning and revision by highlighting the benefits of doing so.

\section{Underpinning rationale and the impact of the CIVA system}

It can be demonstrated that the CIVA system implements the MMU Strategy for Learning, Teaching and Assessment (SLTA) [7] effectively.

Furthermore it can be shown that the CIVA system takes a similar approach in principle to 'constructive alignment' [8][9].

Based on the observations and the experience of myself and other academic staff, some difficulties associated with the characteristics and behaviour of some students have been identified and are listed below. An evidence-based approach has been taken and the CIVA system has been designed to overcome these difficulties and help all students achieve a high quality engineering education outcome.

\section{Difficulties identified:}

(a) Some students lack motivation for formative studies unless they are linked to summative assessment in some way. Some students do not spend enough time on the academic study and give priority to part-time jobs or other activities.

(b) Some students lack the ability and the discipline of self-organising their revision and further study outside the timetabled hours.

(c) The student population has diverse academic background, learning styles, study ability, and personal characteristics, partly due to the widening participation and internationalisation of higher education.

(d) Due to the above reasons, those students do not achieve the required learning outcomes and cannot progress through the course.

\section{Impact of the CIVA system:}

With reference to the dynamics coursework described above, the following observations have been made.

CIVA solves (a) - students became highly motivated to engage with the T\&L activities related to the coursework and devoted a lot of time working on the coursework. 
CIVA solves (b) - the coursework specifications provided guidance on the process and the tasks.

CIVA solves (c) - The coursework spanned over a relatively long period of time. Each student had the opportunity to find learning resources and supports to suit his/her own particular requirements. So, in a sense, their time was utilised in a more optimal way through such a built-in flexibility to achieve an overall improved learning outcome.

CIVA solves (d) - since the coursework related directly to several main topics of the syllabus, the students had understood those topics better through their application in the $\mathrm{V} \& \mathrm{~V}$ process. As a result, the students achieved better results in the final exam.

\section{Potential benefits of the CIVA system in reforming engineering education}

It has been widely accepted that some fundamental reform in engineering education is required. 'A series of reports from The Royal Academy of Engineering (The Royal Academy of Engineering, 2006, 2007, 2010) demonstrates that change in undergraduate engineering education is urgently needed to ensure graduates remain equipped for the new and complex challenges of the $21^{\text {st }}$ century. However, the necessary transformation in the structure and delivery of undergraduate provision has yet to take place across the Higher Education sector.' [10]

To reform the engineering education (with some emphasis on the engineering analysis subjects), I think that the following key issues need to be addressed.

(1) How to maximise the employability status of our course by making the curriculum adaptable to the requirements of the fast evolving engineering world?

(2) How to improve the employability of our graduates by equipping them with the key knowledge, skills and experience of the relevant engineering sector?

(3) How to develop in our graduates the mentality, attitude and ability of professional engineers in taking responsibility and working through complete problem-solving processes?

(4) How to achieve inclusiveness in the global environment that the student intake is increasingly more diverse in multiple dimensions due to internationalization and widening participation in higher education, etc..?

(5) How to make the teaching \& learning effective for students to achieve a high level of attainment?

(6) How to make the academic staff easier to carry out research-informed teaching that will benefit all (the student, the staff, the course and the university)? 
It can be demonstrated that the CIVA system provides a solution to these issues. The statements below are based mainly on the experience and observations in implementing the CIVA system in my teaching.

The CIVA addresses (1) - The major coursework is a project by nature and that is the best platform to develop a problem-solving process by applying a coherent set of knowledge, skills and technologies. Such process is generic to any engineering endeavour. How well the course can react and adapt to the new requirements or trends of future employment depends on the academics who keep themselves well-informed and can incorporate those requirements and trends into the coursework contents.

The CIVA addresses (2) - The coursework is a problem-solving process that mimics the working style of professional engineers. The methods, techniques and the tools used can be industry standard. So the knowledge, skills and experience gained will raise their employability profile directly. Some students produced an excellent coursework report that would impress the potential employer in more than one way if they brought it to an interview for relevant jobs.

The CIVA addresses (3) - To complete the coursework, the student will have to go through the process of working out the solution to the set problem. The V\&V requires the student to take responsibility for his/her own work by checking the results, both the solution and the model, with a professional approach and rigorous procedure. The $V \& V$ is in practice an iterative debugging process and it is an effective driver for quality learning and character building. Often $V \& V$ keeps the students motivated to investigate. This process develops in students the mentality, attitude and ability of professional engineers.

The CIVA addresses (4) - The coursework provides flexibility in time, space, use of different learning resources, etc. for students and therefore can accommodate the differences among students in many ways and to a high degree.

The CIVA addresses (5) - To make the teaching \& learning effective for students to achieve a high level of attainment, the students must be motivated. The summative nature of the coursework as well as the employability-packed feature of the coursework is an effective motivator.

The CIVA addresses (6) - Engineering research has the generic characteristics that it starts from the fundamental principles of the discipline, it applies a body of relevant knowledge and uses a set of tools (theoretical, computational, experimental and their integration) to generate a solution to some new challenge, and it requires the evidence that the solution is valid. Even though the validity of the final solution is the measure of success, it often requires the V\&V of intermediate stages to ensure that the process of deriving the solution is sound and to make debugging easier if the final solution fails. Research-informed 
teaching should also show students such solution-generating processes and let them have the opportunity to practise in order to make the teaching and learning effective. This can only be made possible by student coursework. Academic staff would be interested in such research-informed teaching.

\section{Conclusion}

This paper has demonstrated that the CIVA system can bring about a range of desirable outcomes to engineering education including

- Motivating, guiding, supporting and training students in their learning process

- Enhancing student employability through the discipline-representative problem-solving type of coursework that integrates the application of multiple key skills and provides a valuable experience similar to that found in professional engineering jobs

- Improving inclusiveness mainly due to the built-in flexibilities of the coursework and the active support mechanism

- Improving student's learning outcome by linking the coursework contents to the taught topics within the unit

Further development of the CIVA system aims to enhance its capability of adapting to individual needs of both the learners and the employers.

It is promising that the CIVA system will make a positive contribution to the modernisation of engineering education. This is because the CIVA system or similar will encourage more people to study engineering due to its inclusive appeal, can help more students pursue their own dreams due to its value-adding capability, and will facilitate seamless connections between engineering education and engineering professions due to its employability focused approach. 


\section{References}

1. Morell, L. (2010) Engineering education in the 21st century: Roles, opportunities and challenges. Available at:

https://luenymorell.files.wordpress.com/2010/12/morell-eng-edu-in-21stcent-roles-opport-and-challenges.pdf

2. Hockings, C. (2010) Synthesis inclusive learning and teaching in higher education: A synthesis of research. Available at:

https://www.heacademy.ac.uk/sites/default/files/inclusive_teaching_and_le arning_in_he_synthesis_200410_0.pdf

3. Ryan, J. (2012) Academic shock: Thoughts on teaching international students. Available at: http://www.theguardian.com/higher-educationnetwork/blog/2011/may/18/teaching-international-students

4. Center, the (2015) Recent survey Debunks myths about how college students spent their time - GoodCall news. Available at:

https://www.goodcall.com/news/how-college-students-spend-their-timemay-surprise-you-recent-survey-debunks-myths-03479

5. Lo, S. H. R. (2007) Virtual Mechanical Engineering Education - A Case Study. World Academy of Science, Engineering and Technology, vol. 33, 229-234.

6. Lo, S. H. R. (2016) Verification and Validation as a Key Driver in Modern Engineering Education. IRA International Journal of Education and Multidisciplinary Studies (ISSN 2455-2526), 4(1). doi:http://dx.doi.org/10.21013/jems.v4.n1.p18

7. CELT (2016) MMU strategy for learning, teaching and assessment. Available at: http://www.celt.mmu.ac.uk/ltastrategy/index.php

8. Biggs, J.B. (2003) Aligning teaching for constructing learning. Available at: https://www.heacademy.ac.uk/sites/default/files/resources/id477_aligning_ teaching_for_constructing_learning.pdf

9. Biggs, J.B. and Tang, C. (2011) Teaching for quality learning at university what the student does. 4th ed. Maidenhead: McGraw-Hill/Society for Research into Higher Education/Open University Press.

10. Graham, R. (2012) Achieving excellence in engineering education: The ingredients of successful change. Available at: http://www.raeng.org.uk/publications/reports/achieving-excellence-inengineering-education 